\title{
GAIA Level 2 Ectopic Pregnancy
}

National Cancer Institute

\section{Source}

National Cancer Institute. GAIA Level 2 Ectopic Pregnancy. NCI Thesaurus. Code C128711.

GAIA Level 2 Ectopic Pregnancy is defined by three criteria: first, it does not qualify as a Level 1 Ectopic Pregnancy; second, gestational age is within the pre-defined range for the selected ectopic pregnancy definition as assessed by maternal and/or fetal parameters (Level 1-2) (Brighton Preterm Birth Gestational Age algorithm); third, at least one of the following two requirements must be met: a) Transvaginal ultrasound showing no intrauterine pregnancy; OR b) No products of conception found on endometrial curettage after dilation and curettage procedure. 